venues (such as beaches or who have access to private swimming pools) to establish estimates of exposure to risk;

- an investigation of the circumstances surrounding the drowning of children aged 0-6 years in NSW;

- assessment of the feasibility of using community health centres as a contact point for drowning prevention information;

- a feasibility trial of using a Safe Community partnership model to distribute drowning prevention information and increase the number of people in a given area who either learn or renew their skills in resuscitation techniques;

- assessment of how differently-sized local government councils approach the issue of compliance with regulations regarding backyard swimming pools, including an analysis of the management issues confronting the councils;

- a survey to assess the perceptions of water safety and use of aquatic areas in rural and remote locations in NSW;

- a survey of local government councils regarding the type of information that is held regarding swimming pools owned by their residents;
- an investigation of fatalities of people rockfishing over the last 10 years in NSW.

The vision and ultimate outcome sought through the implementation of the NSW Water Safety Framework 2001-2003 will be a reduction in the trend in the annual rate of drownings, near-drownings, and water-related incidents in NSW.

For more information about the NSW Water Safety Taskforce visit the Web site at www.safewaters.nsw.gov.au.

\section{REFERENCES}

1. NSW Injury Risk Management Research Centre. Analysis of Drowning in Australia and Pilot Analysis of Near Drowning in NSW. Australian Water Safety Council: Sydney, 2000.

2. Public Health Division. Patterns of Injury Costs, NSW 199596. Sydney: NSW Department of Health, 1998.

\title{
MID NORTH COAST ABORIGINAL INJURY SURVEILLANCE PROJECT
}

\section{Jenny Heslop \\ Mid North Coast Area Health Service}

Little is known about the prevalence, nature, and cause of injury experienced by Aboriginal people, or the effect that injury has on the individual, the family, and the community. Until recently the most comprehensive analysis of injury in Aboriginal communities was the Study of Injury in Five Cape York Communities completed in April 1997. ${ }^{1}$

With resources provided by the NSW Department of Health, the Mid North Coast Aboriginal Injury Surveillance Project has replicated elements of the methodology used in the Cape York Study. The project sought to describe patterns of injury, identify risk factors, and formulate responses that improve the health of Aboriginal people residing within the Mid North Coast Area Health Service. ${ }^{2}$ This article briefly describes the report of the project.

The Mid North Coast Aboriginal Injury Surveillance Project commissioned a study that analysed emergency department data and hospital separation data over a 12- month period from 1 July 1999 to 30 June 2000. The study also employed qualitative methods including eventnarratives, semi-structured interviews, and focus groups. These quantitative and qualitative methods were combined to identify and describe the injury experiences of the local Aboriginal community. In addition, the study attempted to determine the accuracy of identification of Aboriginal status recorded in routine data collections.

The study uncovered layers of contributing factors that perpetuate the frequency, severity, and risks associated with injury experienced by the local Aboriginal community. The main factors contributing to injury rates included poor environmental management, inadequate access to services and facilities, and a lack of societal opportunity in relation to employment and social activity.

An immediate outcome from the report has been the acknowledgment by local Aboriginal communities of the significant role that they can play in reducing the risks associated with injury. This potential role includes identification of acceptable opportunities for future coordination, and the cooperation of various health providers and other agencies to enable a positive change 
in relation to the frequency and severity of injury within their communities.

To develop and maintain effective injury prevention partnerships, it is essential for the Aboriginal communities and all other stakeholders to be equally involved throughout the process. Local Aboriginal communities will have ultimate control over the scope and future of any initiatives or partnerships, which must be built on openness, trust, commitment, and sustainability.

Since the publication of the Mid North Coast Aboriginal Injury Surveillance Project Report, the project has successfully developed an inter-sectoral working party for the purpose of putting the recommendations of the report into action. The current priority for the working party is the development and implementation of an Aboriginal Injury Prevention Better Practice Model.
Copies of the Mid North Coast Aboriginal Injury Surveillance Project Report: Pride, Respect and Responsibility can be downloaded from the NSW Department of Health's Web site at www.health.nsw.gov.au/public-health/ health-promotion/improve/injuryprev/pdf/ abinjuryncoast.htm.

\section{REFERENCES}

1. Gladman D, Hunter E, McDermott R, Merritt T, Tulip F. Study of Injury in Five Cape York Communities. Adelaide: AIHW National Injury Surveillance Unit, 1997.

2. Mid North Coast Aboriginal Health Partnership. Mid North Coast Aboriginal Injury Surveillance Project Report: Pride, Respect and Responsibility. Port Macquarie: Mid North Coast Aboriginal Health Partnership, 2001.

\section{CHILD DEATHS AND INJURIES IN DRIVEWAYS}

\section{Rebecca Mitchell}

Injury Prevention and Policy Unit

NSW Department of Health

The Commission for Children and Young People's NSW Child Death Review Team 1998-99 Report found that, between 1996 and 1999, 17 children died after being reversed-over in home driveways in NSW. ${ }^{1}$ The number of children injured in this way was much higher. ${ }^{1}$ For example, between 1996 and 1998, 32 severely-injured children were admitted to the New Children's Hospital at Westmead alone, after being reversed-over in home driveways. $^{1}$

A review by the Motor Accidents Authority of NSW (MAA) suggests that child deaths and injuries in driveways are best tackled through a range of preventive measures. ${ }^{2}$ The review, which responds to the NSW Child Death Review Team 1998-99 Report, calls for a mixture of prevention strategies, including: public education, new vehicle design, and building planning reforms.

The majority of casualities are children under two years of age; the injury was most likely to occur in the driveway of the family home or of other homes in the neighbourhood; and the vehicles involved were large, such as four-wheel drives or commercial vehicles. ${ }^{2}$

The recommendations of the MAA review include:

- encouraging government, community, and private sector organisations to incorporate driveway safety material into their existing programs;

- encouraging the use of lenses and mirrors that facilitate a view of the area immediately behind motor vehicles, especially large vehicles;
- researching the effectiveness and availability of electronic sensing devices for installation on the rear of motor vehicles;

- consulting with the Australian Building Codes Board to look at standards for the construction of driveways;

- furthering research into incidence figures and other related issues.

The MAA review was developed using the services of a broadly-based committee that included Kidsafe NSW, the NSW Roads and Traffic Authority, the NSW Department of Health, the New Children's Hospital, the NRMA, the Institute of Early Childhood, and the NSW Commission for Children and Young People.

A copy of Child Deaths and Injuries in Driveways: Response to the Recommendations of the NSW Child Death Review Team 1998-99 Report can be downloaded from the Motor Accidents Authority of NSW Web site at www.maa.nsw.gov.au/pdf/ ChildFatalities.pdf.

\section{REFERENCES}

1. NSW Child Death Review Team. NSW Child Death Review Team 1998-99 Report. Sydney: Commission for Children and Young People, 2000.

2. Henderson M. Child Deaths and Injuries in Driveways: Response to the Recommendations of the Child Death Review Team 1998-99 Report. Sydney: Motor Accidents Authority of NSW, 2000. 